\title{
MATING SYSTEMS AND POPULATION STRUCTURE IN TWO CLOSELY RELATED SPECIES OF THE WHEAT GROUP
}

\section{CHIASMA FREQUENCY AND POPULATION STRUCTURE*}

\author{
J. HILLEL \\ The Laboratory of Applied Genetics, The Hebrew University, Rehovot, Israel \\ M. W. FELDMAN \\ Department of Biological Sciences, Stanford Unversity, Stanford, California \\ and \\ G. SIMCHEN \\ Department of Genetics, The Hebrew University, Jerusalem, Israel
}

Received 20.vii.72

\begin{abstract}
SUMmary
Correlations between chiasma frequencies and population means and variances of 36 quantitative characters were calculated for seven populations of the predominantly selfing species Triticum longissimum and five populations of the outcrossing species Triticum speltoides. Significant negative correlations between the interstitial chiasma frequencies and both means and variances are found in the selfing species. This coincides with predictions from recent theoretical work concerning selection for degree of recombination. The positive correlations between some of the means and variances and the chiasma frequencies for the outcrosser are explained by the existence of supernumerary chromosomes which have been shown elsewhere to increase interstitial chiasma frequency.
\end{abstract}

\section{INTRODUCTION}

THE first paper in this series (Hillel et al., 1973a) compared the total, between populations, and within-family variances for 36 quantitative characters in the two closely related species from the wheat group, Triticum longissimum and Triticum speltoides. The former is a predominantly selfing species while the latter is primarily an outcrosser (Zohary and Imber, 1963). In that study, seven populations of the selfer and five of the outcrosser were analysed and the within-family variance in $T$. longissimum was found to be considerably higher than that in T. speltoides. Simple analytical considerations based on the theory of quantitative inheritance for a single gene systems with inbreeding proved inadequate to explain this without involving extremely strong selection. This therefore remains an unresolved issue.

In the second paper (Hillel et al., 1973b) we presented the means and variances for what was termed the $\mathrm{S}_{1}$ generation data-namely that generated after a generation of selfing in the experimental plots. These and the $\mathrm{S}_{0} \dagger$ results (progeny of original samples) of the first paper were correlated with environmental variables and it was shown that while the selfer can be found

* Research supported in part by National Institutes of Health Grant USPHS 10452-09-10.

$\dagger$ The detailed description of how the $S_{0}$ and $S_{1}$ generations were obtained is presented in the first two papers. 
in widely varying environments the outcrosser is fairly narrow in the range of its environments.

In this note we have examined correlations of the chiasma characteristics of the two species (Zarchi et al., 1972) with the character means and variances obtained in our previous work (Hillel et al., 1973a). Other authors have demonstrated correlations between chiasma frequency and population parameters. Rees and Ahmad (1963) reported that chiasma frequency in Lolium perenne is highly correlated with longevity and Sun and Rees (1964) showed the same to be true for rye. Crowley (1969), working with Lolium multiflorum, showed that Cooper's (1960) index of perenniality is highly correlated with chiasma frequency. Crowley (loc. cit.) also showed that there is a significant negative correlation between the variance of flowering time and chiasma frequency. In our study we can observe the effect of the breeding system as well as other population characteristics since our two species are very closely related. We present data on the correlations for the 36 characters with chiasma frequency, both in terms of the means and variances of the characters, and after some theoretical arguments which could explain the results in terms of concepts from classical population genetics.

\section{Experimental Design, Material AND methods}

The basic design has been presented in detail by Hillel et al. $(1973 a, b)$. All means and variances reported here are taken from those studies. The investigation of chiasma frequency was presented by Zarchi et al. (1972) and the correlations presented here and based on their data. The reader should also refer to the latter for details of the cytological examination and the scoring of chiasmata.

\section{Results}

Tables 3, 5 and 6 of Hillel et al. (1973a) summarise the means, total variances and within-family variances of the $S_{0}$ generation while the means and within-family variances of the $S_{1}$ generation are reported in Hillel et al. $(1973 b)$, tables 2 and 3, respectively. We have adapted the data presented graphically by Zarchi et al. (1972) figs. 2 and 3, for the mean total number of chiasmata and the mean number of interstitial chiasmata for the twelve populations. These are given in table 1.

\section{TABLE 1}

Total and interstitial chiasma frequency of the $\mathrm{T}$. longissimum and T. speltoides populations

$\begin{array}{cccc}\text { Species } & \text { Population } & \text { Total Xmata } & \text { Interstitial Xmata } \\ \text { T. longissimum } & 1 & 13.69 & 0.70 \\ & 2 & 13.52 & 0.47 \\ & 3 & 14.00 & 2.20 \\ & 4 & 13.74 & 0.73 \\ & 5 & 13.80 & 1.05 \\ & 6 & 13.45 & 0.75 \\ \text { T. speltoides } & 7 & 13.47 & 0.60 \\ & 8 & 13.27 & \\ & 9 & 13.27 & 0.64 \\ & 10 & 13.24 & 0.13 \\ & 11 & 13.27 & 0.26 \\ & 12 & 13.26 & 0.20 \\ & 12 & & 0.18\end{array}$


$T_{\text {ABLE }} 2$ Correlations between $X$ ma frequencies and variances"

$V_{1}=$ Total population variance in generation $S_{0} \quad V_{2}=$ Within $S_{0}$ family variance in generation $S_{0}$ $V_{2}=$ Within $S_{1}$ family variance in generation $S_{1}$

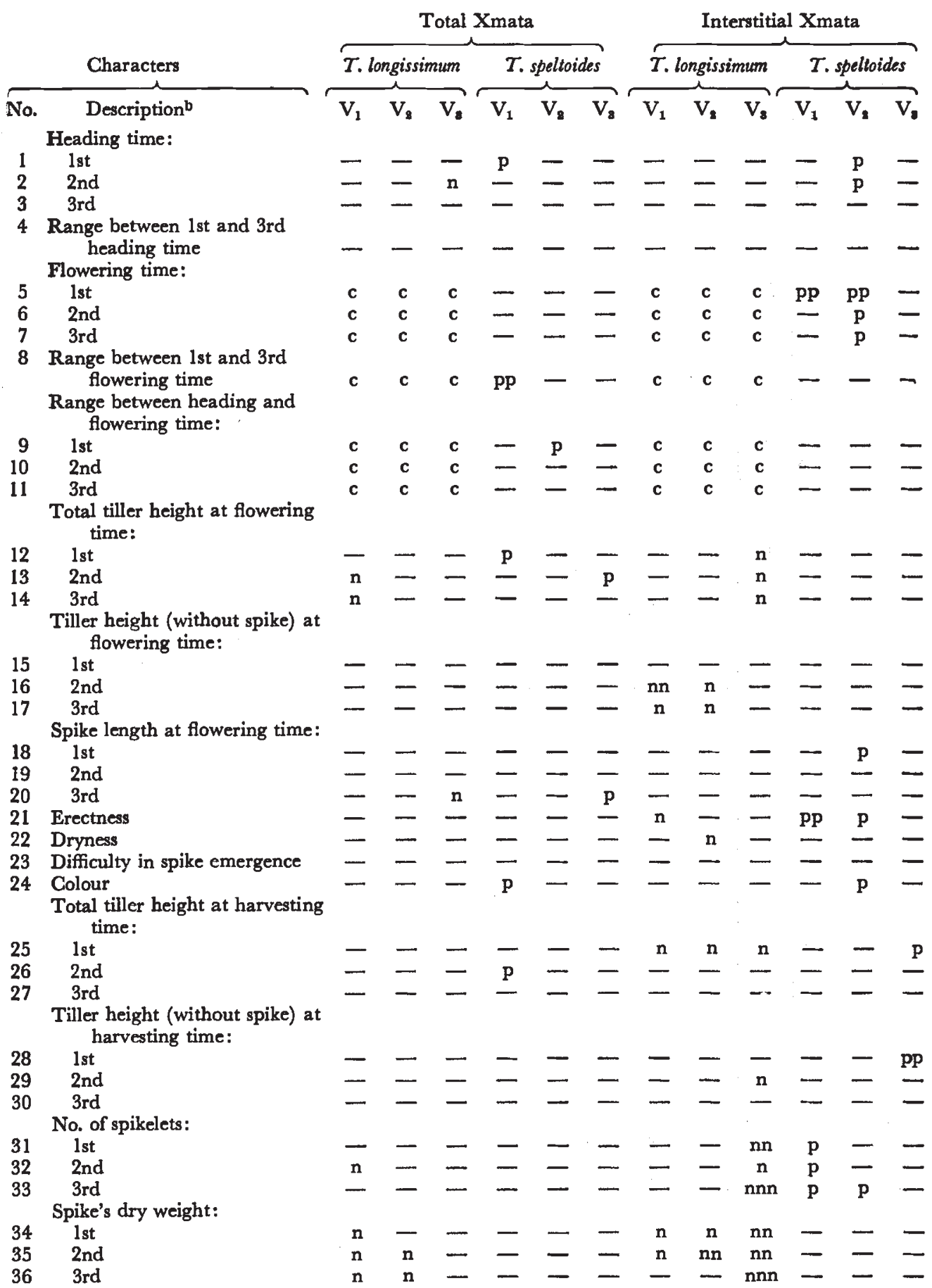

a The number of populations in $T$. longissimum is 7 (d.f. $=5$ ) and in $T$. speltoides is 5 (d.f. $=3$ ).

b 1st, 2nd and 3rd refer to measurements on the first three spikes to flower.

c Population 3 of $T$. longissimum was not measured for flowering time, therefore correlation coefficients were not calculated for characters 5-11 in T. longissimum.

p Positive significant correlation $0.05 \geqslant P>0.01$.

n Negative significant correlation $0.05 \geqslant P>0.01$.

pp Positive significant correlation $0.01 \geqslant \mathrm{P}>0.001$, similarly $\mathrm{nn}$ for negative correlation. nnn Negative significant correlation $P \leqslant 0.001$. 


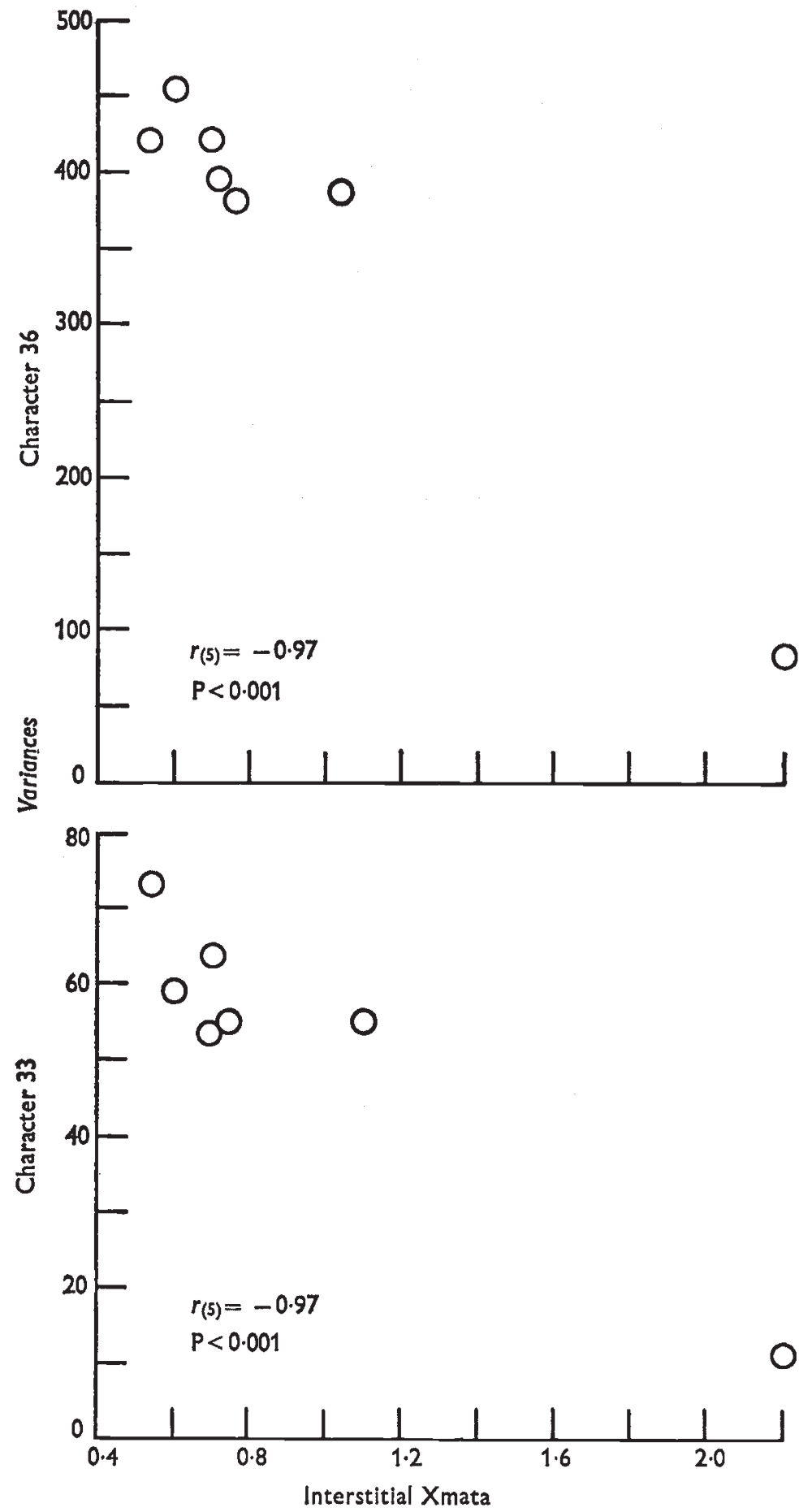

Frg. 1.-Relationship between interstitial chiasmata and the variance within $S_{1}$ families in generation $S_{1}$, for the seven populations of $T$. longissimum. 
Table 3

Correlations between $X$ ma frequencies and means ${ }^{\mathrm{a}}$

$S_{0}=$ the population mean in generation $S_{0}$

$S_{1}=$ the population mean in generation $S_{1}$

Total Xmata

\section{Characters}

$\begin{array}{lc}\text { No. } & \text { Description } \\ & \text { Heading time: } \\ 1 & \text { lst } \\ 2 & 2 \text { 2nd } \\ 3 & \text { 3rd } \\ 4 & \text { Range between 1st and 3rd } \\ \text { heading time } \\ \text { Flowering time: } \\ 5 & \text { 1st } \\ 6 & \text { 2nd } \\ 7 & \text { 3rd } \\ 8 & \text { Range between 1st and 3rd } \\ & \text { flowering time } \\ & \text { Range between heading and } \\ \text { flowering time: }\end{array}$

$\overbrace{\mathrm{S}_{0} \mathrm{~S}_{1}}^{\mathrm{S}_{\mathrm{S}} \text { longissimum }} \overbrace{\mathrm{S}_{0}}^{T \text {. speltoides }}$

Interstitial Xmata

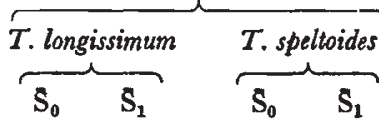

$\begin{array}{llll}- & - & - & - \\ - & - & - & - \\ - & - & - & - \\ \text { c } & \text { c } & - & - \\ \text { c } & \text { c } & - & - \\ \text { c } & \text { c } & - & - \\ \text { c } & \text { c } & \text { p } & -\end{array}$

$\begin{array}{llll}c & \text { c } & - & - \\ \text { c } & \text { c } & - & - \\ \text { c } & \text { c } & - & -\end{array}$

$= \pm$

$=\overline{-}$

$\begin{array}{llll}- & - & - & - \\ c & \text { c } & - & - \\ \text { c } & \text { c } & - & - \\ \text { c } & \text { c } & - & - \\ \text { c } & \text { c } & - & -\end{array}$

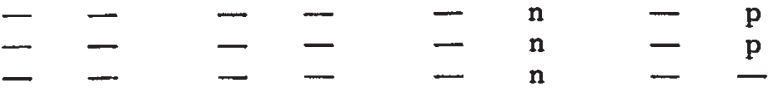

Tiller height (without spike) at flowering time:

$\begin{array}{ll}15 & 1 \mathrm{st} \\ 16 & 2 \mathrm{nd}\end{array}$

17 3rd

Spike length at flowering time:

18 lst

19 2nd

20 3rd

21 Erectness

22 Dryness

23 Difficulty in spike emergence

24 Colour

Total tiller height at harvesting time:

$\begin{array}{ll}25 & \text { 1st } \\ 26 & \text { 2nd } \\ 27 & \text { 3rd }\end{array}$

Tiller height (without spike) at harvesting time:

$\begin{array}{ll}28 & \text { 1st } \\ 29 & \text { 2nd } \\ 30 & \text { 3rd } \\ & \text { No. of spikelets: } \\ 31 & \text { 1st } \\ 32 & \text { 2nd } \\ 33 & \text { 3rd } \\ & \text { Spike's dry weight } \\ 34 & \text { 1st } \\ 35 & \text { 2nd } \\ 36 & \text { 3rd }\end{array}$

See Table 2 for meaning of $n, p$ and notes $a, b, c$. 

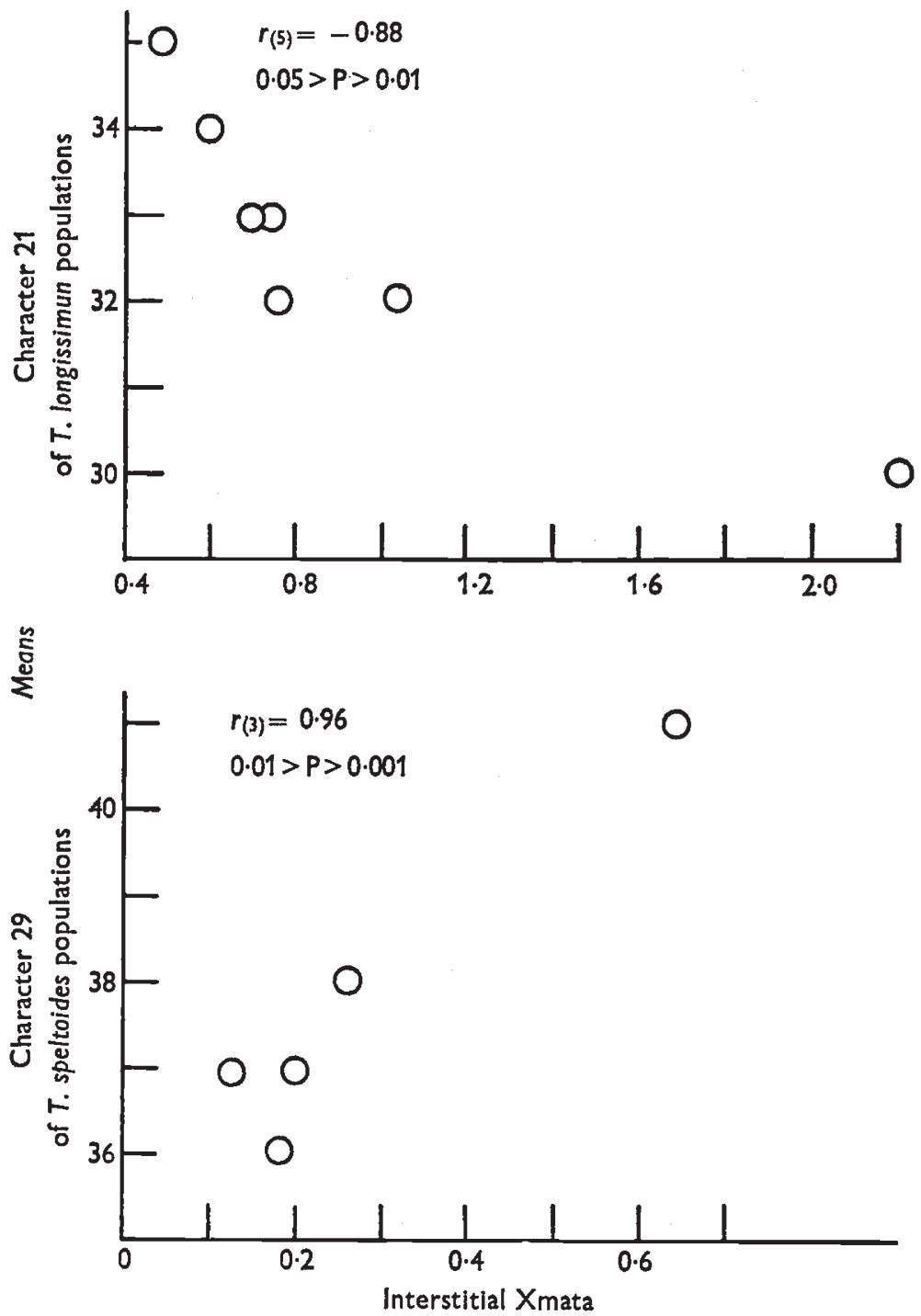

Frg. 2.-Relationship between interstitial chiasmata and the means of generation $S_{1}$.

Table 2 and fig. 1 provide information on the significance of the correlations between both the total and interstitial chiasma frequencies and the three variances of interest, namely the total variance in generation $S_{0}\left(V_{1}\right)$, the within $S_{0}$ families variance in generation $S_{0}\left(V_{2}\right)$ and the within $S_{1}$ families variance in generation $S_{1}\left(V_{3}\right)$. Correlations between the mean chiasma frequencies and the $S_{0}$ and $S_{1}$ population means are presented in table 3 and fig. 2.

It can be seen that few means or variances of either species are correlated with total chiasma frequencies. This result in $T$. speltoides is due to the absence of variation between the total chiasmata means of the various populations (see table 1). The picture is somewhat different for the interstitial 
chiasma frequencies, however. For $T$. longissimum, 12 of the 29 characters showed a significant negative correlation between the within $S_{1}$ family variances and the interstitial chiasma frequencies. In $T$. speltoides, nine of the 36 characters showed a positive correlation between the within $S_{0}$ family variances and the interstitial chiasma frequencies. In the latter species, it appears that the correlated variances are dispersed among the characters. That is, except for characters 5, 6 and 7, they do not appear in groups of three similar characters as is the case with $T$. longissimum.

The total chiasma frequencies are again not correlated with means (table 3). However, for 12 of the $29 \mathrm{~S}_{1}$ characters in $T$. longissimum and 13 of the $36 S_{1}$ characters in $T$. speltoides the means are correlated with the interstitial chiasma frequencies, and again the correlations are negative in the selfer and positive in the outcrosser.

We have found, therefore, that total chiasmata frequencies do not appear to be related to the variances $\left(V_{1}, V_{2}\right.$ and $\left.V_{3}\right)$ or means $\left(S_{0}\right.$ and $\left.S_{1}\right)$ while the interstitial chiasmata are correlated with these measures. In the selfer the significant correlations with means and variances are negative, while in the outcrosser they are positive.

\section{Discussion}

It has been suggested by Zarchi et al. (1972) that terminalised associations may have little to do with recombination but that their primary function could be the physical one of proper disjunction and segregation. Our findings would appear to add force to this argument since the total chiasma frequency is uncorrelated with either aspect of the population structure (means or variances) we have considered. On the other hand, interstitial chiasmata presumably do involve substantial chromosome recombination and would be assumed to influence variability. The data appear to validate this prediction.

Hillel, Simchen and Jinks (1972) have shown that in terms of classical population genetics the within $S_{1}$ families variance for simple quantitative characters increases with increasing heterozygote frequency. In terms of the relationship between the frequency of recombination and expected amount of heterozygosity, the negative correlations observed between the within $S_{1}$ families variance of the selfer and interstitial chiasma frequency is therefore of considerable interest. The rationale for this is as follows. There have been several studies recently on the problem of the evolution of linkage groups and selection for linkage modification in general (Nei, 1967, 1969; Feldman, 1972). This work has been addressed to randomly mating populations and the principle finding has been that under a selective regime allowing linkage disequilibrium between loci (i.e. multiple heterozygotes exist in unequal frequencies), the linkage between these genes will tend to tighten; i.e. recombination between them will decrease. Feldman and Balkau (1973) have considered the same problem for a purely selfing population. In this model, with selection strong enough to allow polymorphism to be maintained, tight linkage will also be favoured. The conditions for this statement to be true will presumably become milder for models with mixed selfing and random mating. However, from the above-mentioned results it would be concluded that the correlation between recombination fraction and heterozygote frequency would be expected to be negative since the selection for 
linkage reduction would decrease as the selection for heterozygotes decreased. In the same way, where heterozygote advantage is weak or absent, increased recombination (combined with occasional outcrossing) will maintain a minimum amount of variability. In light of the above, positive correlations between within $S_{0}$ families variances in the outcrosser and frequencies of interstitial chiasmata are difficult to explain.

It is, we believe, important to note from table 2 that the significant correlations for $T$. speltoides are interspersed among the characters in an inconsistent way, which could indicate that a factor or factors not considered in the model situations might be operating. The answer may lie in the properties of supernumerary chromosomes which have been found in populations 8 and 9 of T. speltoides (Simchen et al., 1971; Zarchi et al., 1972). It appears that most of the significant correlations are due to population 8 which has the highest interstitial chiasma frequency among the $\mathcal{T}$. speltoides populations (see table 1). Zarchi et al. and Simchen et al. (loc. cit.) found that six out of 17 plants tested in population 8 had supernumerary chromosomes. Population 9 had two plants out of 16 with supernumerary chromosomes, while in none of the others were they found. In a more recent study, Zarchi et al. (1973) found 38 plants out of 45 and 21 out of 87 to carry B chromosomes in populations 8 and 9, respectively. Hewitt and John (1967) demonstrated in a species of grasshopper that the Bchromosome content was correlated positively with chiasma frequency. The same was shown for the interstitial chiasmata in our population 8 by Zarchi (personal communication). Furthermore, inspection of table 2 of the present paper and table 6 of Hillel et al. (1973a) shows that for those characters whose correlations with chiasma frequency are significant in $\mathcal{T}$. speltoides, the within $\mathrm{S}_{0}$ families variance in population 8 is markedly greater than in all other $\mathcal{T}$. speltoides populations. It appears, therefore, that the supernumerary chromosomes might have affected the characters, and since they have also an increasing effect on interstitial chiasmata, positive correlations between the variances and interstitial chiasmata could result.

Acknowledgment.-We thank Dr B. John for his comments on the manuscript.

\section{REFERENGES}

COOPER, J. P. 1960. Short-day and low-temperature induction in Lolium. Anns. Bot., 24, 232-246.

CROWLEY, J. G. 1969. Chiasma frequency and longevity in Lolium multiflorum. Heredity, 24, 181-188.

FELDMAN, M. W. 1972. Selection for linkage modification. I. Random mating populations. Theor. Pop. Biol.., 3, 324-346.

feldman, M. W., AND Balkav, B. 1973. Some results in the theory of three gene loci. Proc. Symp. Populations Dynamics. Academic Press, New York.

HEWITT, G. M., AND JOHN, B. 1967. The B chromosome system of Myrmeleotettix maculatus (THUNB). III. The statistics. Chromosoma, 21, 140-162.

HILLEL, J., SIMCHEN, G., AND JINKs, J. L. 1972. Generalised selfing series as an experimental design. I. Theory. Theor. Pop. Biol., 3, 466-490.

HILLEL, J., FELDMAN, M. W., AND SIMCHEN, G. 1973a. Mating systems and population structure in two closely related species of the wheat group. I. Variation between and within populations. Heredity, 30, 141-167.

HILLEL, J., SIMCHEN, G., AND FELDMAN, M. W. 1973b. Mating systems and population structure in two closely related species of the wheat group. II. Environmental factors and population structure. Heredity, 30, 73-83.

NEI, M. 1967. Modification of linkage intensity by natural selection. Genetics, 57, 625-626. 
NEI, M. 1969. Linkage modification and sex difference in recombination. Genetics, 63, 681699.

REES, H., AND AHMAD, K. 1963. Chiasma frequencies in Lolium populations. Evolution, 17, 575-579.

SIMCHEN, G., ZARCHI, Y., AND HILLEL, J. 1971. Supernumerary chromosomes in the second outbreeding species of the wheat group. Chromosoma, 33, 63-69.

SUN, s., AND REEs, H. 1964. Genotypic control of chromosome behaviour in rye. III. Unadaptive heterozygotes. Heredity, 19, 357-367.

ZARCHI, Y., SIMCHEN, G., HILLEL, J., AND sChAAP, T. 1972. Chiasmata and the breeding system in wild populations of diploid wheats. Chromosoma, 38, 77-94.

zohARY, D., AND IMBRR, D. 1963. Genetic dimorphism in fruit types in Aegilops speltoides. Heredity, 18, 223-231. 
